\title{
RESPONSE TO SYMPATHETIC NERVE STIMULATION AND NORADRENALINE IN ATRIA TREATED WITH RESERPINE AND IN ATRIA FROM RABBITS PRETREATED WITH RESERPINE
}

\author{
NOBORU TODA, YOSHIHIDE YAMASAKI \\ AND MOTOHATSU FUJIWARA \\ Department of Pharmacology, Faculty of Medicine, Kyoto University, Sakyo-ku, Kyoto
}

Received for publication May 14, 1970

It is widely known that cardiac noradrenaline is markedly depleted by pretreatment of animals with reserpine (1) but only slightly reduced by treatment of the isolated heart with reserpine $(2,3)$. Pretreatment of animals with reserpine depresses the retention of exogenous noradrenaline in the heart (4) by reducing the uptake of the amine by storage granules (5) and by increasing the destruction of the amine by monoamine oxidase in sympathetic nerve terminals (6). Reserpine when applied in vitro significantly inhibits the uptake of the amine by the isolated heart (7). Reserpine is shown to disappear almost completely from the body in a few hours when injected intravenously (8) but when applied in vitro it acts directly on the heart until the drug is washed out repeatedly. Modification by reserpine of the cardiac functions and the responsiveness of the isolated heart to endogenous and exogeneous noradrenaline would be attributed to the marked depletion of cardiac noradrenaline, the inhibition of the amine uptake by the heart and/ or the actions of reserpine per se. Although the positive chronotropic response of the heart to sympathetic nerve stimulation and to indirectly-acting sympathomimetic amines is markedly reduced and the response to noradrenaline is enhanced by pretreatment with reserpine, little is known about the effects of reserpine applied in vitro on the responses to endogenous and exogencous noradrenaline.

The present investigation was undertaken to examine (a) effects of reserpine applied in vitro on the chronotropic response of isolated atria to sympathetic nerve stimulation, tyramine and exogenous noradrenaline, (b) modification of the contractile tension-frequency relationship and of the chronotropic and inotropic effects of noradrenaline by pretreatment of animals with reserpine, and (c) effects of treatment with noradrenaline or dopamine in the presence of monoamine oxidase inhibitor on the chronotropic response of atria from reserpine-pretreated rabbits to tyramine and to sympathetic nerve stimulation.

\section{METHODS}

Studies were carried out on 43 albino rabbits of either sex, weighing 1.8 to $2.2 . \mathrm{kg}$. 
The animals were anesthetized with ether and were killed by exsanguination from both common carotid arteries. The entire heart was isolated and the ventricles were discarded. The left atrium was scparated from the right along the interatrial septum (9). The left atrium preparation, from which the specialized tissues were excluded, was used for investigation of the inotropic effect of reserpine when the frequency of contraction was maintained constant by artificial electrical stimulation. The S-A node-right atrium preparation was used for studies on the chronotropic effects of noradrenaline and reserpine. In order to investigate the effect of reserpine on the chronotropic response to endogenous noradrenaline the sympathetic nerve-atria preparations were preparcd as described in earlier reports $(10,11)$. The isolated specimen was fixed horizontally between hooks with a resting tension of 300 to $450 \mathrm{mg}$ and suspended in a muscle bath containing $60 \mathrm{ml}$ nutrient solution which was maintained at $30^{\circ} \pm 0.5^{\circ} \mathrm{C}$ and gassed with a mixture of $95 \% \mathrm{O}_{2}$ and $5 \% \mathrm{CO}_{2}$. A pair of hooks anchoring the cut end of the left atrium were connected to an electronic stimulator. Hooks fixing the atrial appendage of the left atrium preparation and the S-A node-right atrium preparation and the right atrial appendage of the sympathetic nerve-atria preparation were connected to the arm lever of a force-displacement transducer (Nihonkoden Kogyo Co.). Constituents of the nutrient solution were as follows $(\mathrm{mM}): \mathrm{Na}^{+}, 162.1: \mathrm{K}^{+}, 5.4: \mathrm{Ca}^{++}, 2.2: \mathrm{Cl}^{-}, 157.0$ : $\mathrm{HCO}_{3}{ }^{-}, 14.9$ : dextrose, 5.6. Sixty to ninety minutes were allowed for equilibrating the preparations before measurements were begun. During the equilibration period the left atrium preparation was stimulated at a basic driving frequency of $60 \mathrm{c} / \mathrm{min}$.

The left atrium preparation was driven electrically by rectangular pulses of supramaximal intensity (about twice threshold intensity) with $3.0 \mathrm{msec}$ duration, applied at a frequency of $60 \mathrm{c} / \mathrm{min}$, unless otherwise indicated. The contractile tension-frequency curve was obtained by raising frequency of stimulation stepwise from 6 to $240 \mathrm{c} / \mathrm{min}$ or higher until the atrial contraction failed to follow all the electrical stimuli. Constant frequencies of stimulation were maintained until the steady state contractile tension was attained. The tension-frcquency curve was obtained in drug-free solution, after 10 minutes of exposure to noradrenaline or after 30 and 60 minutes of exposure to reserpine. Right postganglionic extracardiac sympathetic nerve was lifted above the surface of the solution and was stimulated for 3 seconds by a train of rectangular pulses of supramaximal intensity (about twice the threshold intensity) with $1.0 \mathrm{msec}$ duration, applied at frequencies of 1,5 and $20 \mathrm{c} / \mathrm{sec}$. Transmural stimulation was applied for 3 seconds to the S-A node, which has been demonstrated to produce excitation of intracardiac cholincrgic and adrenergic nerve terminals (12). The stimuli applied were pulses of $0.1 \mathrm{msec}$ duration and supramaximal intensity (about twice the threshold intensity), at frequencies of 20 and $100 \mathrm{c} / \mathrm{sec}$. Electrical pulses werc delivered from a Sanei type ES-103 pulse generator.

Contractions of the atrial preparation were displayed on a two channel penwriter. The S-A nodal rate was taken as the mean value of ten measurcments of the cycle length between contractions under steady state conditions and when the maximum positive 
chronotropic response to extracardiac and intracardiac sympathetic nerve stimulation was attained, and was calculated from the maximum cycle length prolonged by intracardiac cholinergic (transmural) stimulation. Absolute values of the atrial rate and the contractile tension were compared before and after noradrenaline in control preparations and preparations from rabbits pretreated with reserpine. The results were expressed as mean values \pm standard errors of the mcans. Comparisons of the results were made using the Student's " $t$ " test.

Drugs were applied directly to the muscle bath. Noradrenaline or tyramine was applied in cumulative concentrations. The amines and the sympathetic ncrve atimulation were applied after 60 minutes of exposure to reserpine. Reserpine in a dose of $0.5 \mathrm{mg} / \mathrm{kg}$ was injected intravenously for successive two days. The animals were killed 16 to 20 hours after the second injection.

l-Noradrenaline hydrochloride, dopamine hydrochloride, tyramine hydrochloride, nialamide hydrochloride (Pfizer-Taito Co.), quinidine sulfate and reserpine (Dainihon Seiyaku) were used. Concentrations of the drugs were expressed in terms of $\mathrm{g} / \mathrm{ml}$ of the salts.

\section{RESULTS}

\section{Atrial rate and contractility}

The rate of the spontaneously-beating right atrium was decreased by reserpine in concentrations higher than $10^{-6} \mathrm{~g} / \mathrm{ml}$, the decrease being dose-dependent (Fig. 1). Slowing of the atrial rate developed gradually until steady state rate was attained after 30 to $60 \mathrm{~min}$ of exposure to the drug. In 3 preparations exposed to the solvent of reserpine $(0.4 \mathrm{mg}$ phosphoric acid, $50 \mathrm{mg}$ propylenglycol and $80 \mathrm{mg}$ dextrose in $1 \mathrm{ml}$ ) for $60 \mathrm{~min}$ in a volume of $0.3 \mathrm{ml}$ (same as the volume of reserpine solution making the concentration in the muscle bath $5 \times 10^{-8} \mathbf{g}$ / $\mathrm{ml})$ no significant alterations in the atrial spontaneity and contractility were observed. Significant slowing of the atrial rate was observed in preparations from rabbits pretreated with reserpine (Fig. 1).

Contractile force of the left atrium driven electrically was not affected by $10^{-6} \mathrm{~g} / \mathrm{ml}$ of reserpine but was reduced progressively at $5 \times 10^{-6} \mathrm{~g} / \mathrm{ml}$ (Fig. 2-I). At this concentration the reduction of the tension developed

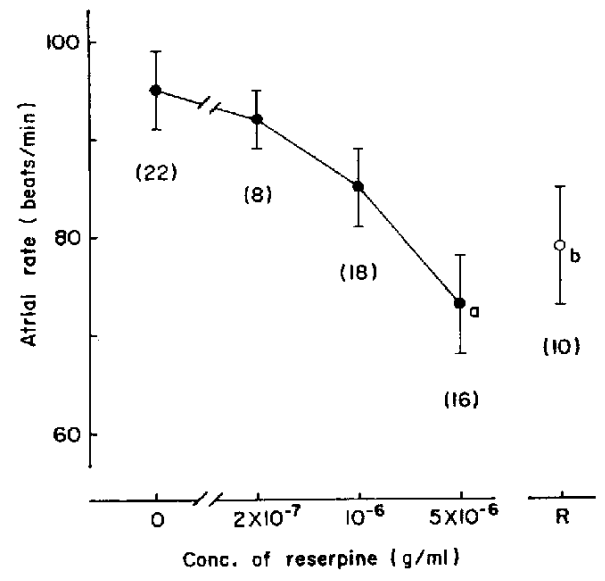

Fig. 1. Alterations in the rate of spontaneously-beating atria induced by reserpine applicd in vitro and by pretreatment of animals with reserpine. Preparations were exposed for 60 minutes to various concentrations of reserpine. $\mathrm{R}$ : reserpine $(0.5 \mathrm{mg} / \mathrm{kg}$ i.v., 2 days)-pretreatment. Figures in parentheses indicate the number of preparations. a : significant difference from control (" 0 " on the abscissa), $P<0.01 . \quad b: P<0.02$. 

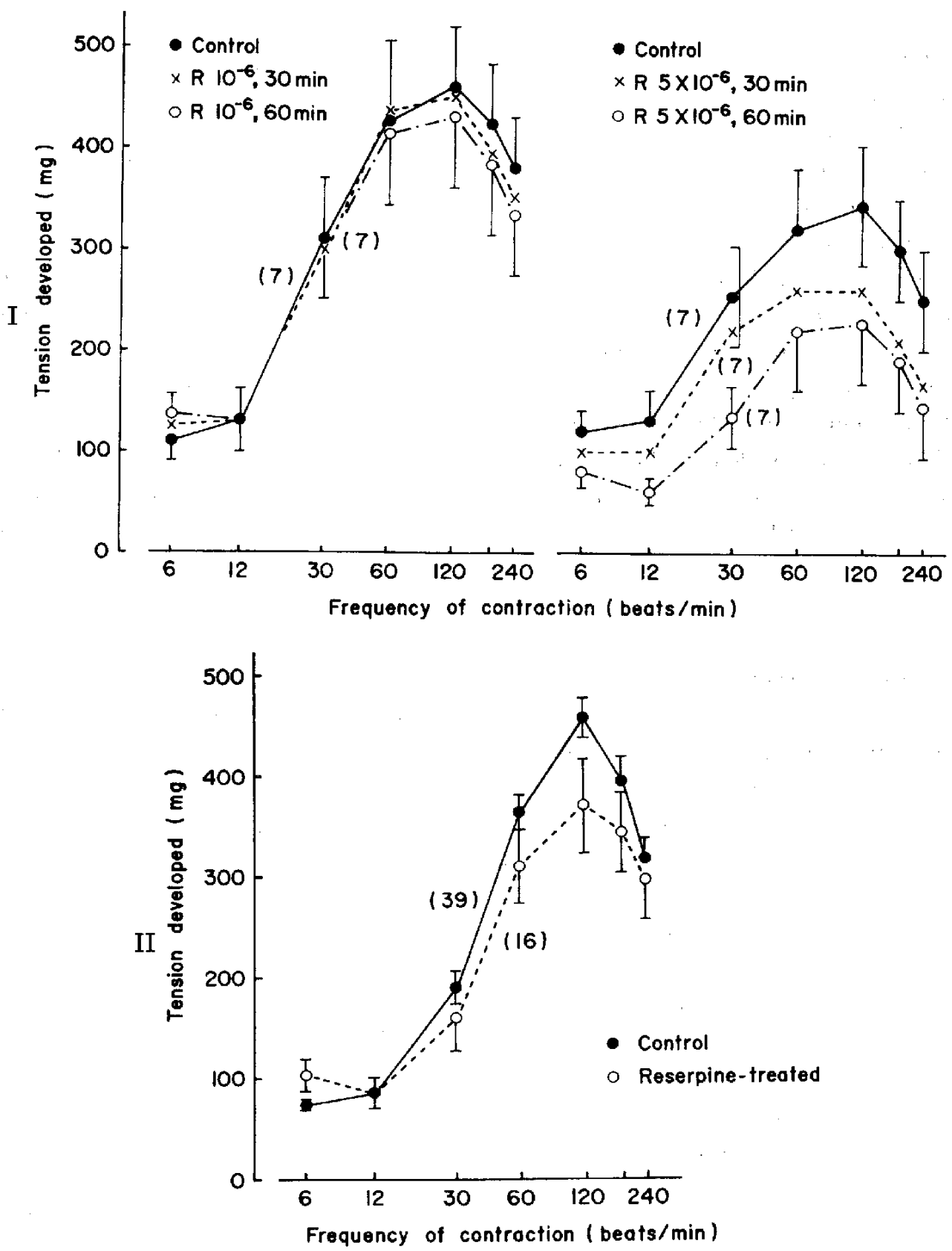

Fig. 2. Effects of reserpine on the contractile tension-frequency curve of the left atrium. I : reserpine applied in vitro. II : pretreatment of rabbits with reserpine. Figures in parentheses indicate the number of preparations.

at high frequencies ( 30 to 240 beats/min) was more marked than that at low frequencies (6 and 12 beats/min). In order to analyse the responsiveness of atrial myocardium to rapid stimulation, both the maximum driving rate at which the amplitude of two succes- 
TABLE 1. Effects of reserpine and quinidine on the values of $R_{1}$ and $R_{2}$.

$R_{1}$ and $R_{2}$ : see text. $R=$ reserpine; Reserpinized=atria from reserpine-pretreated rabbits ; $Q=$ quinidine ; $N A=$ noradrenaline. $N=$ number of experiments. $N . S .=$ nonsignificant.

\begin{tabular}{|c|c|c|c|c|c|c|}
\hline & & $\mathrm{N}$ & $\mathrm{R}_{1}$ (beats/min) & $\mathbf{P}$ & $\mathbf{R}_{\mathrm{g}}$ (beats $/ \mathrm{min}$ ) & $\mathrm{P}$ \\
\hline \multicolumn{2}{|l|}{ Control } & 7 & $220 \pm 24$ & & $360 \pm 18$ & \\
\hline \multirow[t]{2}{*}{$\mathrm{R} 10^{-6} \mathrm{~g} / \mathrm{ml}$} & $30 \mathrm{~min}$ & 7 & $230 \pm 36$ & N.S. & $350 \pm 18$ & N.S. \\
\hline & $60 \mathrm{~min}$ & 7 & $220 \pm 24$ & N.S. & $320 \pm 24$ & N.S. \\
\hline \multirow[t]{2}{*}{$\mathrm{R} 5 \times 10^{-6} \mathrm{~g} / \mathrm{ml}$} & $30 \mathrm{~min}$ & 7 & $200 \pm 18$ & N.S. & $280 \pm 24$ & $<0.05$ \\
\hline & $60 \mathrm{~min}$ & 6 & $200 \pm 18$ & N.S. & $270 \pm 24$ & $<0.02$ \\
\hline \multicolumn{2}{|l|}{ After wash } & 6 & $180 \pm 24$ & N.S. & $220 \pm 24$ & $<0.01$ \\
\hline \multicolumn{2}{|l|}{ Control } & 16 & $220 \pm 12$ & & $350 \pm 18$ & \\
\hline \multicolumn{2}{|l|}{ Reserpinized } & 16 & $190 \pm 12$ & N.S. & $340 \pm 12$ & N.S. \\
\hline \multicolumn{2}{|c|}{ Reserpinized $+\mathrm{NA} 10^{-7} \mathrm{~g} / \mathrm{m}^{2}$} & 16 & $200 \pm 18$ & N.S. & $340 \pm 18$ & N.S. \\
\hline \multicolumn{2}{|l|}{ Control } & 9 & 220 上 24 & & $340 \pm 18$ & \\
\hline \multirow[t]{2}{*}{$Q 10^{-6} \mathrm{~g} / \mathrm{ml}$} & $30 \mathrm{~min}$ & 7 & $200 \pm 24$ & N.S. & $320 \pm 18$ & N.S. \\
\hline & $60 \mathrm{~min}$ & 3 & $200 \pm 24$ & N.S. & $320 \pm 42$ & N.S. \\
\hline \multirow{2}{*}{$Q 10^{-5} \mathrm{~g} / \mathrm{ml}$} & $30 \mathrm{~min}$ & 9 & $190+12$ & N.S. & $230 \pm 12$ & $<0.01$ \\
\hline & $60 \mathrm{~min}$ & 3 & $180 \pm 36$ & N.S. & $200 \pm 24$ & $<0.01$ \\
\hline \multirow[t]{2}{*}{ Q $5 \times 10^{-5} \mathrm{~g} / \mathrm{ml}$, } & $30 \mathrm{~min}$ & 8 & $70 \pm 6$ & $<0.01$ & $80 \pm 12$ & $<0.01$ \\
\hline & $60 \mathrm{~min}$ & 2 & 60 & & 60 & \\
\hline \multicolumn{2}{|l|}{ After wash } & 4 & $140 \pm 18$ & $<0.01$ & $180 \pm 6$ & $<0.01$ \\
\hline
\end{tabular}

sive contractions was the same $\left(={ }^{\text {" }} \mathrm{R}_{1}\right.$ ") and the maximum rate at which alternating contractions were produced in which the amplitude of the smaller contractions was not less than one-third the amplitude of the larger contractions ( $=R_{2} "$ ) (9) were measured. The value of $R_{2}$ was reduced with increasing concentrations of reserpine, whereas the value of $R_{1}$ was not significantly affected by reserpine (Table 1 ). The effect of $5 \times 10^{-0}$ $\mathrm{g} / \mathrm{ml}$ of reserpine on the $R_{2}$ was less potent than that of $10^{-5} \mathrm{~g} / \mathrm{ml}$ of quinidine but much more potent than that of $10^{-6} \mathrm{~g} / \mathrm{ml}$ of quinidine. The reduction of the contractile tension and of the $R_{2}$ produced by high concentrations of reserpine was not corrected by repeated replacement of reserpine solution with fresh solution. The reduction of the $R_{1}$ and the $\mathrm{R}_{2}$ by quinidine was partly corrected by repeated washout.

Pretreatment of animals with reserpine did not produce significant alterations in the tension-frequency curve (Fig. 2-II), although trends of increasing the tension developed at low frequency ( 6 beats $/ \mathrm{min}$ ) and of decreasing the tension at high frequencies (60 to 180 beats $/ \mathrm{min}$ ) werc noted. The mean values of $R_{1}$ and $R_{2}$ did not differ significantly from the values obtained from non-treated preparations (Table 1).

\section{Response to noradrenaline}

The positive chronotropic response to stimulation of extracardiac postganglionic sympathetic nerves was reduced by reserpine in concentrations higher than $10^{-6} \mathrm{~g} / \mathrm{ml}$ (Fig. 3). The duration of the response was significantly shortened by $10^{-6}$ and $5 \times 10^{-6}$ $\mathrm{g} / \mathrm{ml}$ of the drug $(\mathrm{p}<0.05)$. The positive chronotropic effect of noradrenaline was not 
influenced by $10^{-6} \mathrm{~g} / \mathrm{ml}$ of reserpine but was reduced at $5 \times 10^{-6} \mathrm{~g} / \mathrm{ml}$ (Fig. $4-\mathrm{I}$ ). Doseresponse curve of tyramine was not significantly moved by repeated application of the amine (Fig. 5-I). Reserpine at $10^{-6}$ and $5 \times 10^{-6} \mathrm{~g} / \mathrm{ml}$ reduced the positive chronotropic effect of tyramine (Fig. 5-II). The reduction of the effect of tyramine by reserpine was more marked, as compared with that of noradrenaline and sympathetic nerve stimulation.

Depletion of functional noradrenaline from atria was confirmed by testing the chronotropic effect of tyramine in a concentration of $2 \times 10^{-5} \mathrm{~g} / \mathrm{ml}$. In preparations from 16 rabbits pretreated with reserpine tyramine increased the atrial rate slightly $(3 \pm 1$ beats/min, $)$ whereas in non-treated preparations the amine increased the rate by $62 \pm 5$ beats/min $(N=5)$. The positive chronotropic effect of noradrenaline was appreciably augmented in reserpine-pretreated atria, as compared with that in control preparations (Fig. 4-II). Noradrenaline

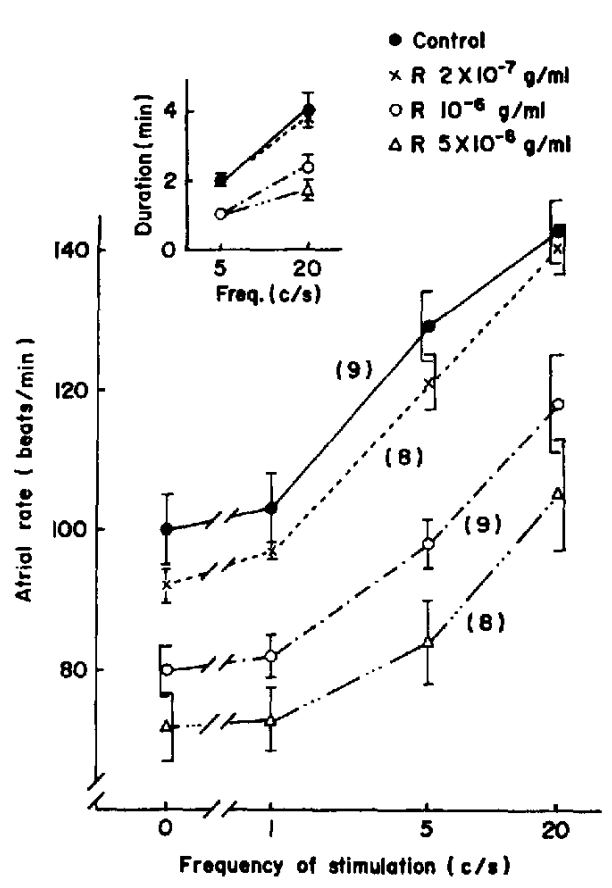

FIG. 3. Modification by reserpine of the positive chronotropic response and the duration of the responsc (upper figure) to sympathetic nerve stimulation. Figures in parentheses indicate the number of preparations.
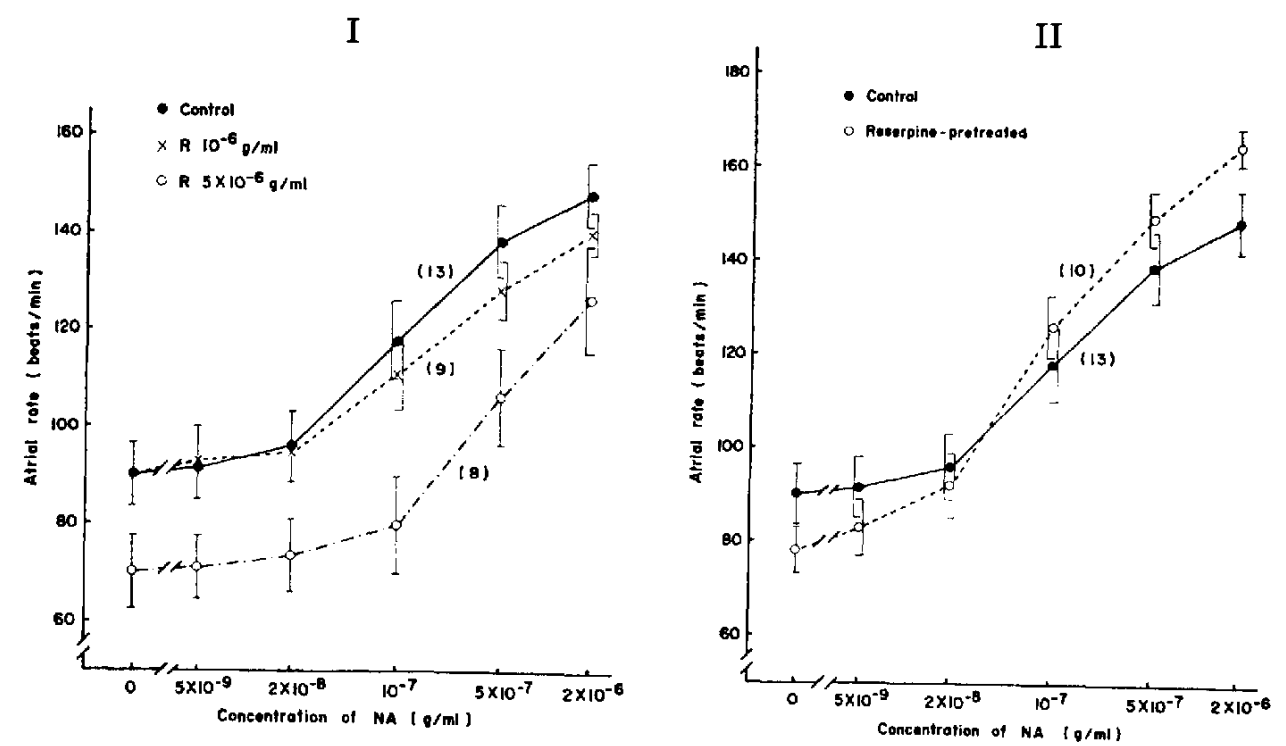

FrG. 4. Modification by reserpine of the positive jchronotropic leffect of noradrenaline. I : reserpine applied in vitro. II : pretreatment of animals with reserpine. 

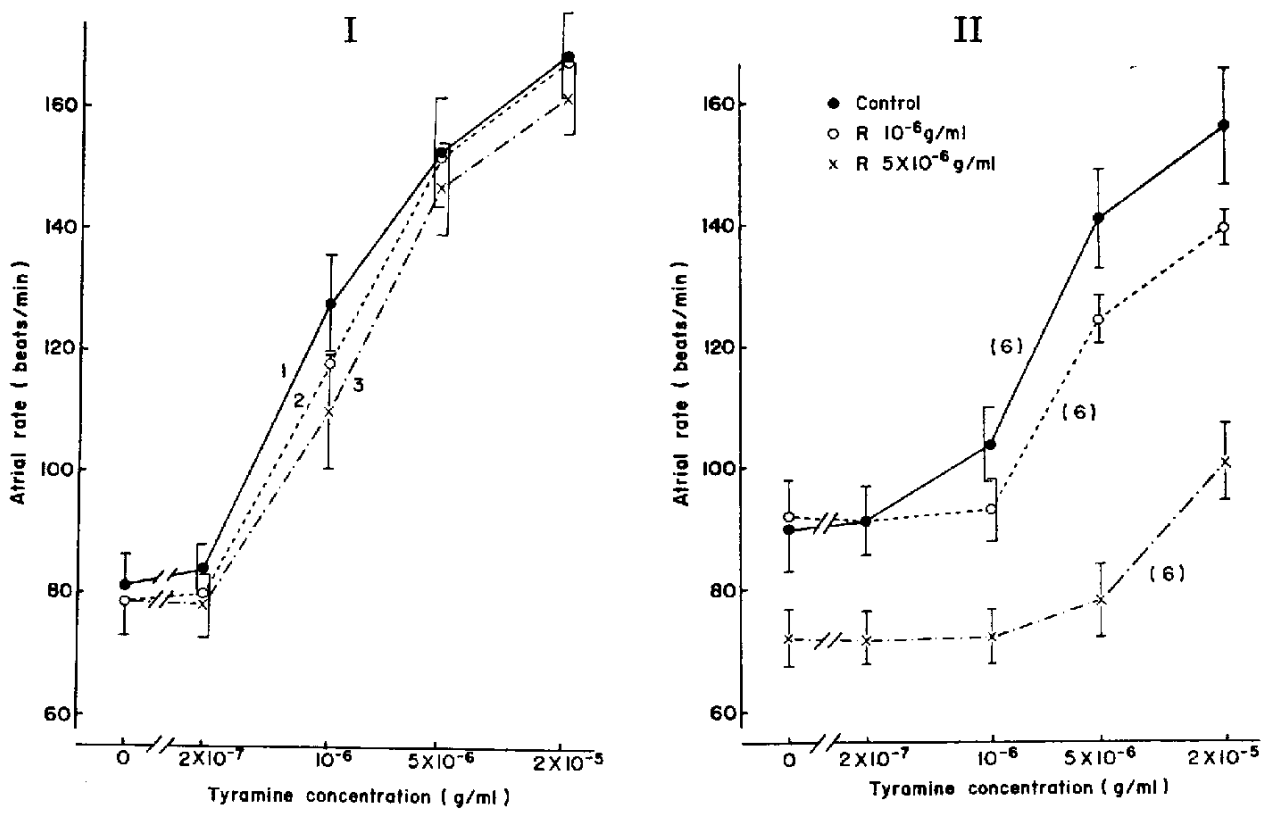

FIG. 5. Tyramine dose-chronotropic re sponse relationship. I : dose-response curves obtained by repeated application of tyramine. 1,2 and $3=1 \mathrm{st}$, $2 \mathrm{nd}$ and $3 \mathrm{rd}$ trial. II : effect of reserpine applied in vitro.

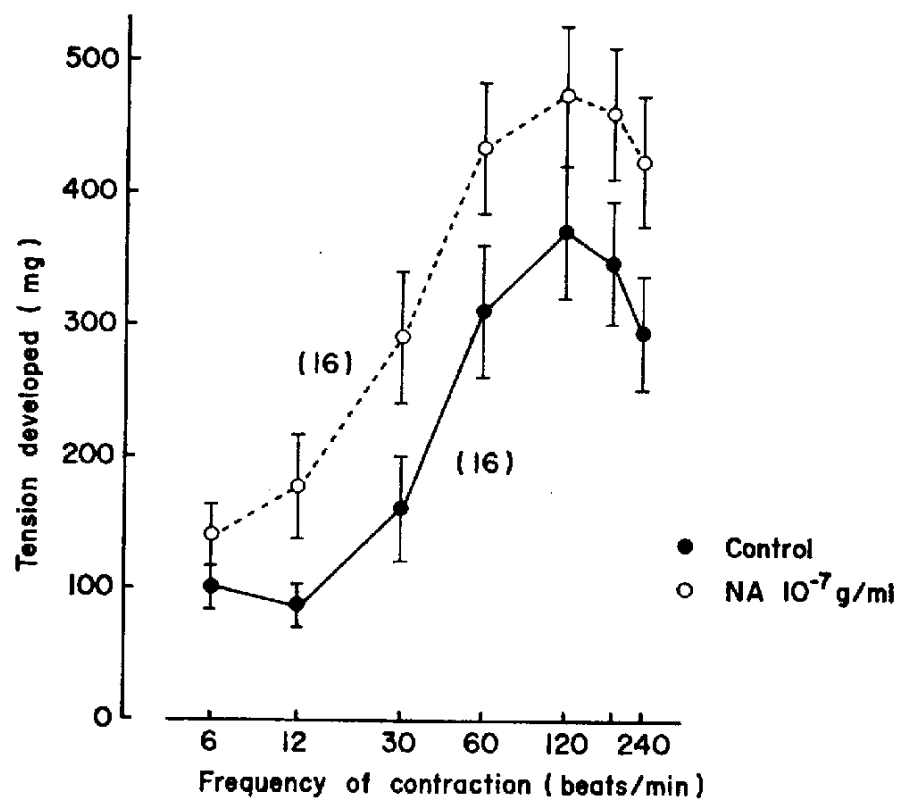

FIG. 6. Alterations in the contractile tension-frequency curve of left atria from reserpine-pretreated rabbits by noradrenaline.

elicited an enhancement of contractile tension of the left atria from rabbits pretreated with reserpine (Fig. 6). The contractile enhancement was dependent upon frequency of contraction, as was that observed in control preparations (9). In control and reserpine- 
pretreated preparations the enhancement did not differ (Fig. 7).

Response to sympathetic nerve stimulation and tyramine in preparations from reserpine-pretreated rabbits

Whether or not sympathetic nerves attached to atria were actually functional could hardly be confirmed in preparations from reserpine-pretreated animals, since the nerve stimulation produced slight or no tachycardia. Therefore, the technique of stimulating intracardiac adrenergic and cholinergic nerve terminals (transmural stimulation) was also used. Slowing of the atrial rate followed by acceleration was elicited by the transmural stimulation. The appropriate location for stimulation of adrenergic and cholinergic nerve terminals is demonstrated in the previous report (13).

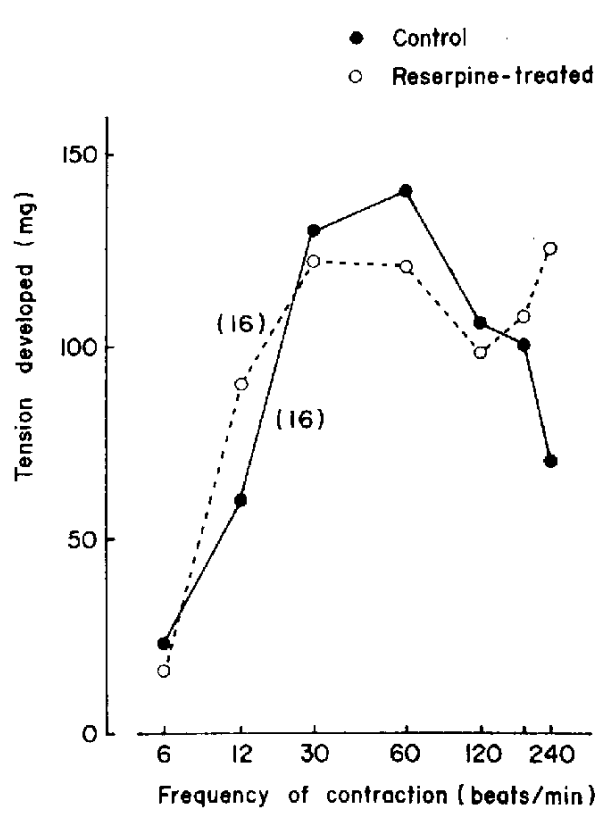

Fig. 7. Increase in the contractile tension of left atria from normal rabbits and from rabbits pretreated with reserpine, caused by $10^{-7} \mathrm{~g} / \mathrm{ml}$ of noradrenaline.

Reserpine-pretreatment abolished or markedly reduced the positive chronotropic and inotropic responses to stimulation of extracardiac and intracardiac sympathetic nerves and to tyramine (Table 2). In 3 of 13 preparations slight slowing of atrial rate was produced by sympathetic nerve stimulation. In reserpine-pretreated preparations in which transmural stimulation increascd the atrial rate by $2.8 \pm 0.4$ beats $/ \mathrm{min}$ (from $79 \pm 8$ to $82 \pm 8$ beats $/ \mathrm{min}, \mathrm{N}=5)$ tyramine $\left(2 \times 10^{-5} \mathrm{~g} / \mathrm{ml}\right)$ significantly potentiated the positive response to the stimulation $(P<0.05)$, the rate increase induced being $5.6 \pm 1.1$ beats/min (from $85 \pm 8$ to $91 \pm 9$ beats $/ \mathrm{min}, \mathrm{N}=5$ ). Atria from rabbits pretreated with reserpine were exposed to $2 \times 10^{-6} \mathrm{~g} / \mathrm{ml}$ of noradrenaline or to $5 \times 10^{-5} \mathrm{~g} / \mathrm{ml}$ of dopamine for $30 \mathrm{~min}$ and washed repeatedly. Thirty to sixty min after wash-out the positive chronotropic effect of sympathetic nerve stimulation and of transmural stimulation was not restored, whereas the effect of tyramine $\left(2 \times 10^{-5} \mathrm{~g} / \mathrm{ml}\right)$ was partially restored. The positive inotropic response to tyraminc was also restored: the contractile force was increased by $27 \%$ in preparations from reserpine-pretreated rabbits and by $170 \%$ after exposure to noradrenaline and wash-out. Treatment with $10^{-4} \mathrm{~g} / \mathrm{ml}$ of nialamide for 5 min did not augment the positive chronotropic effect of transmural stimulation. After exposure to nialamide and noradrenaline $\left(2 \times 10^{-6} \mathrm{~g} / \mathrm{ml}\right)$ for 30 minutes and wash-out, the steady state atrial rate was significantly accelerated. Stimulation of extracardiac and intracardiac sympathetic nerve did not produce measurable acceleration of the atrial rate, whereas tyramine produced a marked tachycardia, the maximum rate induced being close to that obtained in non-treated preparations. The negative chrono- 
TABLE 2. Chronotropic response to stimulation of extracardiac sympathetic nerves and to transmural stimulation. a : negative chronotropic effect $: b$ : positive chronotropic effect $: c$ : preparations treated with the drugs indicated (NA=noradrenaline; DA=dopamine). Preparations were exposed to noradrenaline $\left(2 \times 10^{-6} \mathrm{~g} / \mathrm{ml}\right)$ or dopamine $\left(5 \times 10^{-5} \mathrm{~g} / \mathrm{ml}\right)$ for 30 minutes. Nialamide $\left(10^{-4} \mathrm{~g} / \mathrm{ml}\right)$ was applied 5 minutes before the amines. $\mathrm{N}=$ number of experiments. * : significant difference from values indicated in the column "None", $\mathrm{P}<0.01$. **: $\mathrm{P}<0.02$.

\begin{tabular}{|c|c|c|c|c|c|c|c|}
\hline \multirow{2}{*}{ Procedure } & \multirow{2}{*}{ Parameters } & \multirow{2}{*}{$\begin{array}{l}\text { Non- } \\
\text { treated }\end{array}$} & \multicolumn{5}{|c|}{ Reserpine-pretreated } \\
\hline & & & None & $\mathrm{NA}^{\mathrm{c}}$ & $\begin{array}{l}\text { Nialamide } \\
+\mathbf{N A}^{\mathbf{c}}\end{array}$ & $\mathrm{DA}^{\mathrm{c}}$ & $\begin{array}{l}\text { Nialamide } \\
+\mathrm{DA}^{\mathrm{c}}\end{array}$ \\
\hline \multirow{4}{*}{$\begin{array}{l}\text { Sympath. } \\
\text { stim. } \\
(20 / \mathrm{sec})\end{array}$} & $\mathrm{N}$ & 9 & 13 & 7 & 3 & 5 & 6 \\
\hline & Control rate (beats/min) & $99 \pm 5$ & $79 \pm 5$ & $87 \pm 5$ & $137 \pm 11 *$ & $78 \pm 12$ & $123 \pm 12^{*}$ \\
\hline & Rate after stim. (beats/min) & $142 \pm 4$ & $82 \pm 5$ & $90 \pm 5$ & $138 \pm 11$ & $82 \pm 12$ & $126 \pm 13$ \\
\hline & Rate increase (beats/min) & $43 \pm 5$ & $3 \pm 1$ & $3 \pm 2$ & $1 \pm 1$ & $4 \pm 2$ & $3 \pm 1$ \\
\hline \multirow{5}{*}{$\begin{array}{l}\text { Transmural } \\
\text { stim. } \\
(20 / \text { sec })\end{array}$} & $\mathbf{N}$ & 9 & 14 & 9 & 5 & 5 & 6 \\
\hline & Control rate (beats/min) & $96 \pm 6$ & 78 上 5 & $84 \pm 5$ & $134 \pm 8 *$ & $82 \pm 12$ & $126 \pm 12 *$ \\
\hline & Rate after stim. (beats/min) & $27 \pm 4$ & $30 \pm 4$ & $26 \pm 4$ & $51 \pm 17$ & $32 \pm 6$ & $30 \pm 14$ \\
\hline & Rate after stim.b (beats/min) & $131 \pm 5$ & $80 \pm 5$ & $87 \pm 6$ & $135 \pm 8$ & $86 \pm 11$ & $130 \pm 11$ \\
\hline & Rate increase (beats/min) & $35 \pm 4$ & $2 \pm 1$ & $3 \pm 1$ & $1 \pm 1$ & $4 \pm 1$ & $3 \pm 1$ \\
\hline \multirow{5}{*}{$\begin{array}{l}\text { Transmural } \\
\text { stim. } \\
(100 / \mathrm{sec})\end{array}$} & $\mathrm{N}$ & 9 & 12 & 7 & 6 & 5 & 6 \\
\hline & Control rate (beats/min) & $96 \pm 7$ & $78 \pm 5$ & $85 \pm 6$ & $138 \pm 7 *$ & $82 \pm 12$ & $126 \pm 13^{*}$ \\
\hline & Rate after stim. ${ }^{\mathrm{a}}($ beats $/ \mathrm{min})$ & $22 \pm 3$ & $23 \pm 4$ & $25 \pm 4$ & $46 \pm 14$ & $31 \pm 6$ & $30 \pm 14$ \\
\hline & Rate after stim. ${ }^{b}$ (beats/min) & $136 \pm 6$ & $80 \pm 5$ & $89 \pm 6$ & $140 \pm 7$ & $85 \pm 12$ & $132 \pm 14$ \\
\hline & Rate increase (beats/min) & $40 \pm 5$ & $2 \pm 1$ & $4 \pm 1$ & $2 \pm 1$ & $4 \pm 1$ & $6 \pm 2$ \\
\hline \multirow{4}{*}{$\begin{array}{c}\text { Tyramine } \\
\left(2 \times 10^{-5}\right. \\
\text { g/ml })\end{array}$} & $\bar{N}$ & 5 & 10 & 6 & 6 & 4 & 7 \\
\hline & Control rate (beats/min) & $91 \pm 5$ & $82 \pm 5$ & $88 \pm 3$ & $135 \pm 7 *$ & $85 \pm 15$ & $125 \pm 8^{*}$ \\
\hline & Rate after drug (beatf/min) & $158 \pm 5$ & $88 \pm 6$ & $122 \pm 11$ & $167 \pm 4$ & $115 \pm 18$ & $151 \pm 4$ \\
\hline & Rate increase (beats/min) & $67 \pm 5$ & $5 \pm 1$ & $34 \pm 9 *$ & $33 \pm 5^{*}$ & $30 \pm 10^{*}$ & $26 \pm 8^{* *}$ \\
\hline
\end{tabular}

tropic response to transmural stimulation was reduced. The results are summarized in Table 2. Treatment of atria with dopamine in the presence or absence of nialamide caused the similar results to those obtained upon treatment with noradrenaline.

\section{DISCUSSION}

Pretreatment of animals with reserpine did not significantly alter the contractile force-frequency curve but reduced the spontaneous rate. Using reserpine labelled with ${ }^{14} \mathrm{C}$, Sheppard, Lucas and Tsien (8) have shown that the rat heart attains the maximum concentration of reserpine within 1 hour after intravenous injection and that little remains at the end of 6 hours. Cardiac noradrenaline is markedly depleted by pretreatment of rabbits with reserpine for more than 4 hours (1). According to Whithrington and Zaimis (14), the heart from cats pretreated with $1 \mathrm{mg} / \mathrm{kg}$ of reserpine is in failure. They suggested a striking similarity between the behaviour of the heart poisoned with reserpine and that developing in conditions in which the oxygen supply or the oxygen utilization of the myocardium is decreased. However, despite a moderate reduction of the oxygen consumption of isolated rabbit ventricles by pretreatment with reserpine 
(15), no alteration in the contractile force-frequency curve was elicited. The similar ineffectiveness of reserpine-pretreatment has been demonstrated for cat right ventricular strips and papillary muscles (16) and for atria from hyperthyroid guinea pigs (17). These findings suggest that endogenous noradrenaline stores are not necessary for the production of changes in the contractile force. It is suggested that the values of $R_{1}$ and $R_{2}$, defined as the maximum driving rate which atrial contractions follow (see Results), do not represent directly the refractory period but may provide parameters indicating changes in the cardiac excitability (9). Reserpine-pretreatment did not influence the values of $R_{1}$ and $R_{2}$. In contrast, noradrenaline applied to isolated atria is shown to increase the values of $R_{1}$ and $R_{2}(9)$. Both the relative and the absolute refractory period in the dog ventricle and atrium are shortened when adrenaline or noradrenaline is infused intravenously $(18,19)$.

Reserpine when applied in vitro caused a dose-dependent reduction of the contractile force of isolated left atria. In spite of persistence of reserpine for longer than $60 \mathrm{~min}$, cardiac noradrenaline is only slightly reduced $(2,3)$. The reduction of the contractile force induced by reserpine would not be due to a decrease in functional noradrenaline but to actions of reserpine per se on the atrial myocardium. The effects of reserpine on cardiac functions resemble those of quinidine (20) and propranolol: a marked reduction of the contractile tension developed at high frequencies, a decrease in the values of $R_{1}$ and $R_{2}$, slowing of the spontaneous rate, a prolongation of the action potential duration and a reduction of the action potential amplitude (21). As far as changes in the contractile tension-frequency curve and the values of $R_{1}$ and $R_{2}$ are concerned, the effects of reserpine are similar to those of a reduction in the $\left[\mathrm{Ca}^{++}\right]_{0}$ (9). Nayler (22) suggested that reserpine applied in vitro caused a reduction of intracellular $\mathrm{Ca}^{++}$ available for contraction, following evidence indicating increased efflux of $\mathrm{Ca}^{++}$from driven strips of toad ventricular myocardium.

The positive chronotropic effect of sympathetic nerve stimulation was decreased in atria treated with reserpine in concentrations higher than $10^{-6} \mathrm{~g} / \mathrm{ml}$, while the effect of noradrenaline was not influenced by $10^{-6} \mathrm{~g} / \mathrm{ml}$ of reserpine but was reduced by $5 \times$ $10^{-6} \mathrm{~g} / \mathrm{ml}$. The results would suggest that the reduction of the effect of sympathetic stimulation caused by the lower concentration $\left(10^{-6} \mathrm{~g} / \mathrm{ml}\right)$ of reserpine which is high enough to decrease cardiac noradrenaline (3) is due either to a depletion of functional noradrenaline in sympathetic nerve terminals or to a decrease in the noradrenaline release (23), and that reserpine in the higher concentration $\left(5 \times 10^{-6} \mathrm{~g} / \mathrm{ml}\right)$ reduces susceptibility of adrenergic receptors in atrial pacemaker to noradrenaline. Although reserpine is reported to inhibit the uptake of noradrenaline by the isolated rat heart at similar potency to that of imipramine and cocaine (7), potentiation and prolongation of the chronotropic response to endogenous and exogenous noradrenaline were not produced by reserpine but by desmethylimipramine and cocaine (24). The inhibitory effect of reserpine on adrenergic receptors might mask the proposed cocaine-like potentiation. The more marked inhibition of the chronotropic response to tyramine by reserpine than 
that of sympathetic nerve stimulation would result from a reduced uptake of the amine by noradrenaline storage granules.

It has been shown by Furchgott, Kirpekar, Rieker and Schwab (25) and Trendelenburg (26) that in atria from guinea pigs, rabbits and cats pretreated with reserpine the positive inotropic and chronotropic effects of tyramine were restored but the effects of sympathetic nerve stimulation were not restored after replenishment with noradrenaline. The results obtained from the present study on rabbit atria in response to stimulation of extracardiac and intracardiac sympathetic nerves and to tyramine were consistent with their findings. On the other hand, restoration of the response to sympathetic nerve stimulation has been demonstrated for cat nictitating membrane $(27,28)$, rabbit ileum (29) and guinea pig vas deferens (30). Inhibition of monoamine oxidase increases the capabilities of noradrenaline to restore the inotropic and chronotropic responses of isolated atria to tyramine and other indirectly acting sympathomimetic amines $(31,32)$. The present study was carricd out to reexamine whether the effects of sympathetic nerve stimulation could be restored following replenishment of noradrenaline storage sites of atria in which monoamine oxidase was inhibited by nialamide. Data obtained here proved that inhibition of monoamine oxidase did not render assistance to restoration of the chronotropic response to sympathetic stimulation but markedly potentiated the restoration of the response to tyramine. Evidences indicating that the restorative action of dopamine on the tyramine response is reduced by disulfiram, a dopamine- $\beta$ hydroxylase inhibitor $(32,33)$, and that the amine storage granules contain most of the dopamine- $\beta$-hydroxylase (34) are in favour that dopamine is converted to noradrenaline at this site (32). According to Häggendal and Malmfors (35), in iris of reserpine-pretreated rats exogenous noradrenaline does not enter the proper sites for release by nerve impulses but noradrenaline formed from exogenous dopamine after inhibition of monoamine oxidase is released by nerve stimulation. In atria from reserpine-pretreated rabbits, however, treatment with dopamine after inhibition of monoamine oxidase by nialamide did not restore the response to sympathetic nerve stimulation. The complete dissociation between the response to tyramine and that to sympathetic stimulation after replenishment of the storage sites of atria with exogenous noradrenaline or noradrenaline formed from exogenous dopamine under conditions of monoamine oxidase inhibition would indicate that the restored response to tyramine seems to depend on a storage site that is not accessible to nerve impulses. It is less likely that reserpine-pretreatment interferes with processes coupling excitation of sympathetic nerve terminals with a release of noradrenaline replenished, since the response to sympathetic nerve stimulation is restored in other organs, such as nictitating membrane, ileum and vas deferens.

\section{SUMMARY}

Sympathetic nerve-atria preparations, S-A node-atria preparations and left atrial preparations from normal rabbits and from rabbits pretreated with reserpine $(0.5 \mathrm{mg} /$ kg i.v., 2 days) were used. The rate of the spontaneously-beating atrium was reduced 
by reserpine in concentrations higher than $10^{-8} \mathrm{~g} / \mathrm{ml}$ and by pretreatment of animals with reserpine. The contractile tension-frequency curve of the left atrium was moved downwards by reserpine $\left(5 \times 10^{-6} \mathrm{~g} / \mathrm{ml}\right)$ but was not significantly affected by pretreatment of animals with reserpine. The positive chronotropic response to sympathetic nerve stimulation and to tyramine was reduced by reserpine in concentrations higher than $10^{-6} \mathrm{~g} / \mathrm{ml}$, whereas the chronotropic response to noradrenaline was reduced by $5 \times 10^{-6}$ $\mathrm{g} / \mathrm{ml}$ of reserpine. Pretreatment of rabbits with reserpine shifted the noradrenaline dosc-chronotropic response curve left, but did not affect the positive inotropic effect of noradrenaline. Treatment of atria from reserpine-pretreated rabbits with noradrenaline or dopamine in the presence or absence of a monoamine oxidase inhibitor, nialamide, did not restore the chronotropic effect of stimulation of extracardiac and intracardiac sympathetic nerves but the effect of tyramine. The possible mode of actions of reserpine on the atrial functions and on the chronotropic effect of noradrenaline, sympathetic nerve stimulation and tyramine are discussed.

\section{REFERENGES}

1) Carlsson, A., Rosengren, E., Bertler, A. and Nilsson, J,: Psychotropic Drugs, Edited by S. Garatitini and V. Ghetti, p. 363, Elsevier, New York (1957)

2) Matsuo, T.: Jap. J. Pharmac. 12, 62 (1962)

3) Cervont, P., Kirpekar, S.M. and Schwab, A.: J. Pharmac. exp. Ther. 151, 196 (1966)

4) Iversen, L.L., Glowinski, J. And Axelrod, J.: J. Pharmac. exp. Ther. 150, 173 (1965)

5) Dengler, H.J., Spiegel, H.E. ANd Titus, E.O.: Science, N.Y. 133, 1072 (1961)

6) Kopln, I.J. and Gondon, E.K.: J. Pharmac. exp. Ther. 138, 351 (1962)

7) Iversen, L.L.: The Ubtake and Storage of Noradrenaline in Sympathetic Nerves, University Press, Cambridge (1966)

8) Sireppard, H., Lugas, R.G. and Tsien, W.H.: Archs int. Pharmacodyn. Ther 103, 256 (1955)

9) Toda, N.: Br. J. Pharmac. Chemother. 36, 350 (1969)

10) Toda, N.: J. Physiol. 196, 677 (1968)

11) Toda, N. and Shimamoto, K.: J. Pharmac. exp. Ther. 159, 298 (1968)

12) Vincenzi, F.F. And West, T.C.: J. Pharmac. exp. Ther. 141, 185 (1963)

13) West, T.C. AND TodA, N.: Circulation Res. 20, 18 (1967)

14) Whithrington, P. and Zaimis, E.: Br.J. Pharmac. Chemother, 17, 380 (1961)

15) Toda, N., Fujuwara, M. and Hattori, K.: Jap. J. Pharmac. 15, 234 (1965)

16) Spilker, B. and Cervoni, P.: J. Pharmac. exp. Ther. 168, 60 (1969)

17) Murayama, M. and Goodkind, M. J.: Girculation Res. 23, 743 (1968)

18) Stebens, A.A., Hoffman, B.F., Ensen, J.E., Farrell, J.E. and Brooks, G. MaC.: Am. J. Physoil. 175, 1 (1953)

19) Gilbert, J.I., L.ange, G., Polevoy, I. and Brooks, C. MaC.: J. Pharmac. exp. Ther. 123, 9 (1968)

20) Bıyajy, L.D. and Nash, G.B.: J. Pharmac. exp. Ther. 148, 193 (1965)

21) Toda, N.: Jap. J. Pharmac, 10, 78 (1960)

22) Nayler, W.G.: J. Pharmac. exp. Ther. 139, 222 (1963)

23) Kuno, T., Nishio, H. And Mrsu, Y.: Jap. J. Pharmac. 20, 445 (1970).

24) Matsuo, S. and Toda, N.: Br. J. Pharmac. Chemother. 32, 473 (1968) 
25) Furchgott, R.F., Kirpekar, M., Rieker, M. and Schwab, A.: J. Pharmac. exp. Ther. 142, 39 (1963)

26) Trendelenburg, U.: J. Pharmac. exp. Ther. 147, 313 (1965)

27) Burn, J.H. And Rand, M.J.: Br. J. Pharmac. Chemother. 15, 47 (1960)

28) Trendelendurg, U. and Pfefrer, R.I.: Arch. exp. Path. Pharmak. 248, 39 (1964)

29) Gillespie, J.S. and Mackenna, B.R.: $J$. Physiol. 156, 17 (1961)

30) Hukovié, S.: Br. J. Pharmac. Chemother. 16, 188 (1961)

31) Furchgott, R.F. and Gargia, P.S.: J. Pharmac. exp. Ther. 163, 98 (1962)

32) Murnaghan, M.F.: Br. J. Pharmac. Chemother. 34, 88 (1968)

33) Musacchio, J.M., Bhagat, B., Jagkson, D.J. and Kopin, I.J.: J. Pharmac. exp. Ther. 152, 293 (1966)

34) Potter, L.T. And Axelrod, J.: J. Pharmac. exp. Ther. 142, 299 (1963)

35) HAgggendal, J. and Malmfors, T.: Acta physiol. scand. 75, 33 (1969) 